\title{
Effects of elevated temperatures on glass-reinforced epoxy pipes under multi-axial loadings
}

\author{
Z. S. Nazirah" ${ }^{1}$, M. S. Abdul Majid ${ }^{1,2^{*}}$ and R. Daud ${ }^{1}$ \\ ${ }^{1}$ Schools of Mechatronics Engineering, Universiti Malaysia Perlis, \\ 02600 Arau, Perlis, Malaysia \\ *Email: sitinazirah.zamri@ymail.com \\ Phone: +6049885166; Fax: +6049885167 \\ ${ }^{2}$ Programme of Mechanical Engineering Centre, Universiti Malaysia Perlis, \\ 02600 Arau, Perlis, Malaysia
}

\begin{abstract}
The effects of elevated temperatures on the performance of glass-reinforced epoxy (GRE) pipes under multi-axial loadings were investigated. Finite element software was used to develop the layers of the winding angle on GRE composite pipes. The simulations of the closed-ended pipes' performance under internal pressure loadings of various hoop to axial stress interactions were observed, then the failure strength was illustrated in the form of a failure envelope. Five different stress ratios ranging from pure axial loading 0:1, 1:1, $2: 1,4: 1$ and pure hoop 1:0 were tested at elevated temperatures (room temperature (RT), $65^{\circ} \mathrm{C}$ and $95^{\circ} \mathrm{C}$ ) respectively. The first ply failure (FPF) for GRE pipes was predicted based on Tsai-Wu failure criteria. The results show that the highest temperature reduced the strength of the GRE pipes since the hoop and axial stress decreased with increasing temperature and thus the mechanical properties of the GRE pipes were degraded with the increase of temperature. Both showed a strong dependence on the stress ratio and test temperatures. Moreover, as the temperature increases, the glass fibres become more ductile and cause the failure envelopes to shrink towards the origin and become slightly narrower to accommodate the increase in strength of the composite pipes. It is shown that the initial failure stress based failure envelope at elevated temperatures generally degraded, except for the 2:1 loading where the initial failure stress increased.
\end{abstract}

Keywords: Multi-axial loadings; composite pipes; temperature; finite element; stress ratio.

\section{INTRODUCTION}

A composite material is a material that consists of two or more physically distinct phases, suitably arranged or distributed. The continuous phase is referred to as the matrix, while the distributed phase is called the reinforcement. A glass-reinforced epoxy is light in weight, erosion resistant, high temperature resistant, heat conductive, stiff, light, and with a good appearance [1-5]. Most commonly, E-glass has been the preferred choice of reinforcing fibre used [6-8]. These reinforcing composites are crucial to increase the corrosion resistance and also contribute to the increase in lifetime of the pipe. Filamentwound GRE tubes have been the subject of theoretical and experimental investigations for many years now. One of the areas of interest has always been to evaluate the stressstrain relationship, failure envelopes and failure mechanisms of GRE tubes under biaxial loading. At present, the understanding of their behaviour, particularly under combinations 
of axial tension and internal pressure, is limited by the lack of modelling data and by a lack of understanding of this failure mode [9-12]. The main objective of this work is to provide an improved understanding of the performance of $\pm 55^{\circ}$ glass fibre reinforced epoxy (GRE) pipe under multi-axial loading. The results are compared with those from tests on similar pipes at room temperature, $65^{\circ} \mathrm{C}$ and $95^{\circ} \mathrm{C}$. The results were compared with the experimental initial failure stress data obtained from [6].

\section{MODEL DEVELOPMENT}

All of the pipes used were geometrically similar, with an inside diameter of $200 \mathrm{~mm}$, length of $2000 \mathrm{~mm}, 6 \mathrm{~mm}$ wall thickness and $\pm 55^{\circ}$ winding angle. This angle is commonly encountered since the netting analysis suggests that this is the optimum angle to use in piping systems where the ratio of applied hoop to axial stress is 2:1 [13]. The stress components induced in each ply have to be calculated when the pipe is subjected to internal pressure. The FE method is employed to conduct stress analysis and obtain the stress distribution in structural layers of GRE pipes. Commercial software from the ANSYS workbench was used for this purpose. First of all, the parameters of the material properties as shown in Table 1 were used to verify the materials of the pipe used in this research [14].

Table 1. Material description [14].

\begin{tabular}{ll}
\hline \multicolumn{1}{c}{ Title } & \multicolumn{1}{c}{ Description } \\
\hline Fibre & E-glass \\
Type of fibres & Long and continuous \\
Type of composite & Laminates \\
Matrix & Epoxy \\
Orientation & $\pm 55^{\circ}$ \\
No. of ply & 10 \\
\hline
\end{tabular}

Table 2. The physical and mechanical properties at different temperatures of the GRE composite pipes [15].

\begin{tabular}{lccc}
\hline Physical \& mechanical properties & Room temperature $(\mathrm{RT})$ & $65{ }^{\circ} \mathrm{C}$ & $95{ }^{\circ} \mathrm{C}$ \\
\hline Internal diameter (mm) & 200 & 200 & 200 \\
Average wall thickness (mm) & 6 & 6 & 6 \\
Length of pipes (mm) & 2000 & 2000 & 2000 \\
No. of ply & 10 & 10 & 10 \\
Density, kg/m 3 & 2000 & 2000 & 2000 \\
Eepoxy, MPa & 2800 & 2240 & 1680 \\
Eglass, MPa & 73000 & 58400 & 43800 \\
Eaxial, $\mathrm{MPa}$ & 11724 & 9379.2 & 7034.4 \\
Enoop, MPa & 20455 & 16364 & 12273 \\
E1, MPa & 44920 & 35936 & 26952 \\
E2, MPa & 11406 & 9125 & 6844 \\
Poisson's ratio, $\mathrm{v}_{12}$ & 0.28 & 0.28 & 0.28 \\
Poisson's ratio $\mathrm{v}_{21}$ & 0.071 & 0.071 & 0.071 \\
$\mathrm{G}_{12}, \mathrm{MPa}$ & 4603 & 3682 & 2762 \\
\hline
\end{tabular}


Table 2 summarizes the physical and mechanical properties of GRE composite pipes at different temperatures [16]. The required mechanical properties are calculated using the rule of mixture for the longitudinal Young's modulus and the major Poisson's ratio and Tsai-Wu formulation for the transverse and shear Young's modulus [15]. Figure 1 shows the flowchart for the prediction of failure of GRE composite pipes at elevated temperature conditions. The process to identify the failure models for failed plies (elements) and conduct stiffness degradation proceeds when any failed ply (elements) has occurred. The structure was checked to determine whether it is failed, or vice versa when there are no failed plies. The results obtained will be analysed with the experimental result when the structure has failed. Otherwise, if there is no failed structure, the load will be increased and the process will be repeated again at the stress analysis shown in Figure 1. The whole process will then be repeated for the other temperatures.

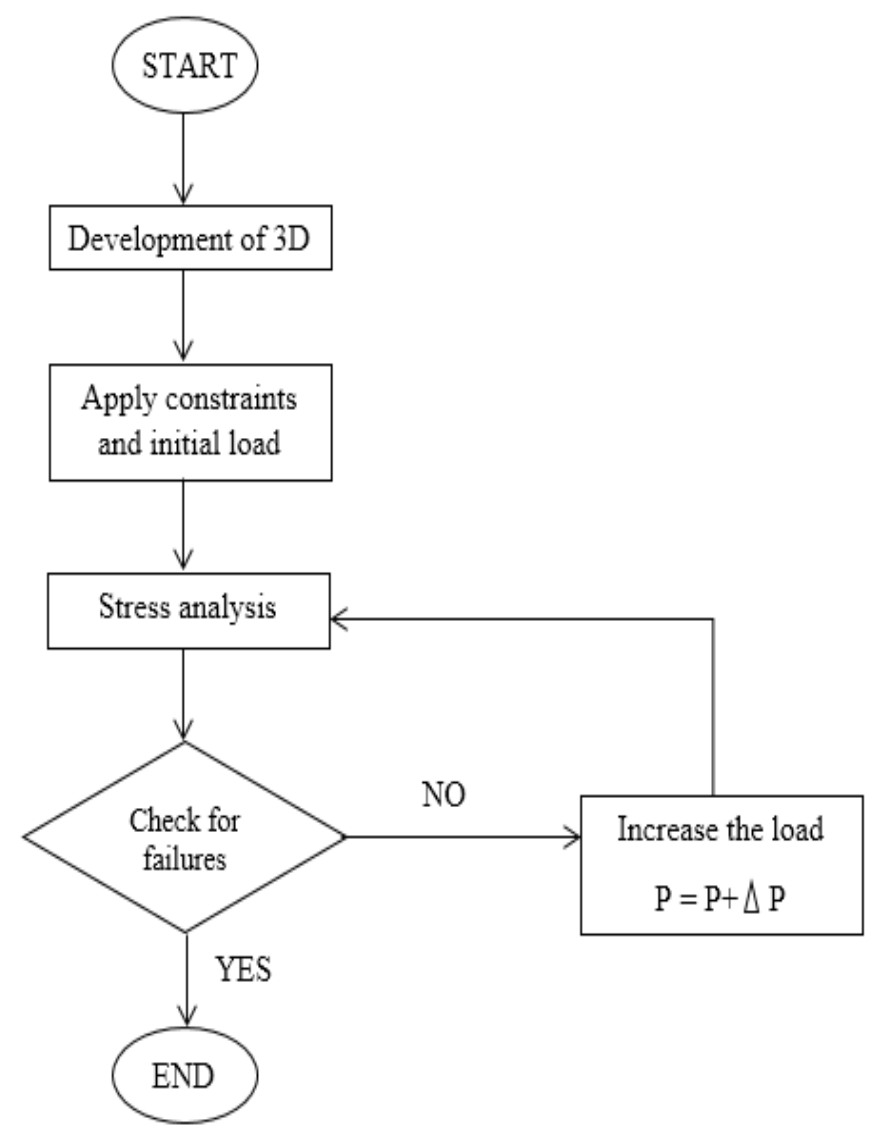

Figure 1. The process flow for the prediction of failure of composite laminates.

\section{Finite Element Mesh Generation}

Figure 2(a) shows the solid model of the pipe while Figure 2(b) shows the meshed model of the GRE pipes. The discretization (mesh generation) was the first and most important step in the finite element analysis, where the results depend on the type of element used for analysis. Tetra elements (3D meshing) were used to mesh the entire geometry for time-saving purposes, the modelling was simple in shape and there is no edge in the model that needs to apply the finest meshing size. In this step the component or part was divided into a number of small parts. In discretization, the number of nodes formed was 9595 and the number of elements was 1730. The purpose of discretization was to perform the analysis on each small division separately. In addition to these parameters, the choice of 
an element type and mesh size to provide reliable results with a reasonable computational time was also important in simulating structures with interface elements.

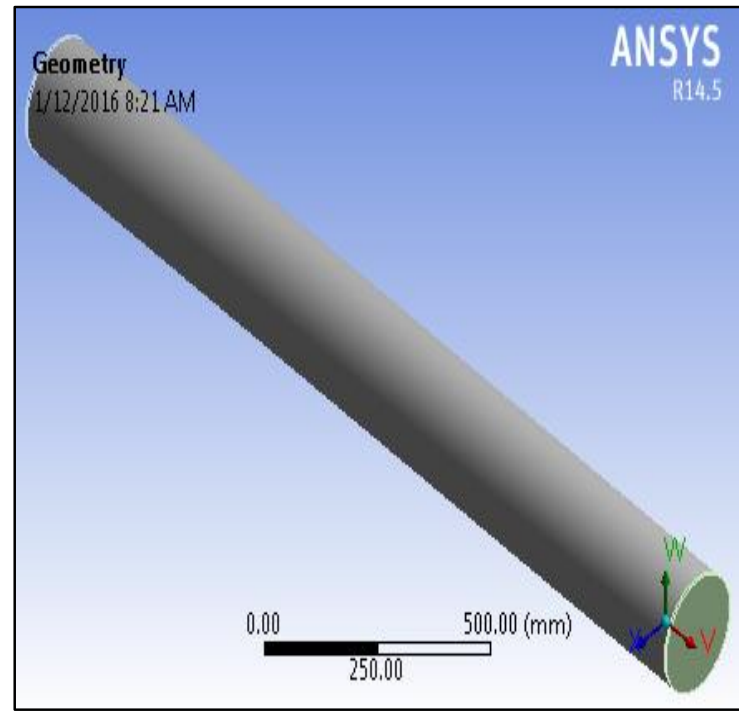

(a)

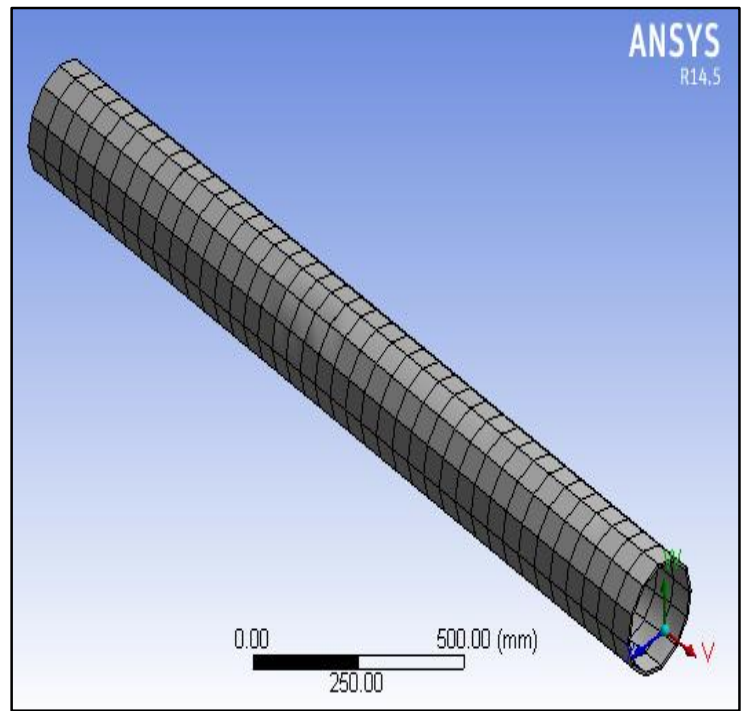

(b)

Figure 2. Modelling development: (a) solid model of GRE pipes; (b) meshed model of GRE pipes.

\section{Loads, Boundary Conditions}

The supports of both end points in the model are fixed (fully fixed in all degrees of freedom) as shown in Figure 3, which also shows the internal pressure loading that is applied to the inner surface of the composite pipes. There is no other constraint or loading in this analysis.

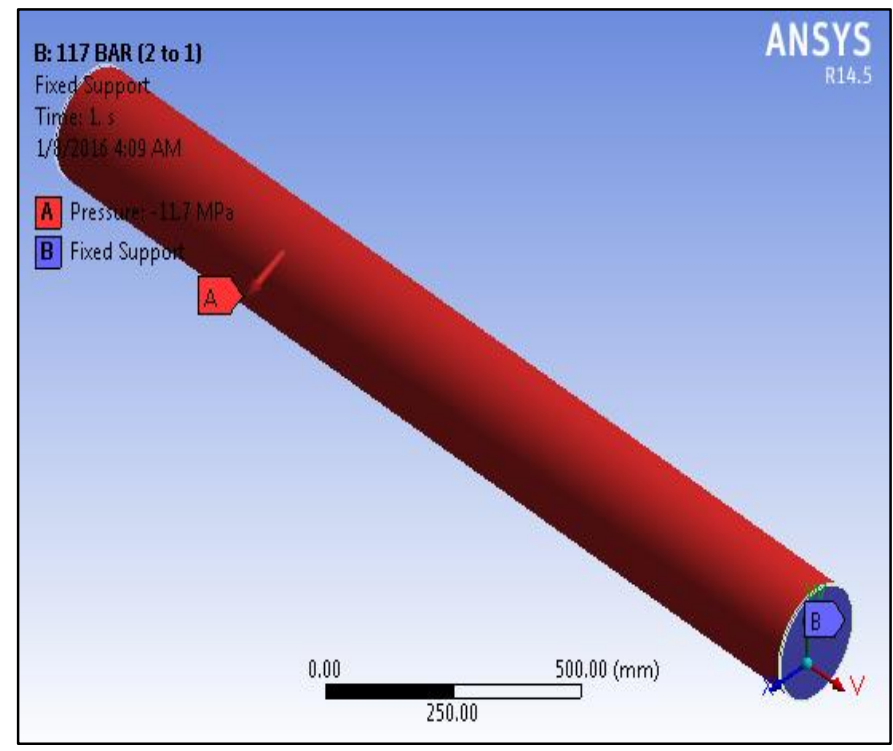

Figure 3. Load and boundary conditions applied on GRE pipes. 


\section{Structural Analysis of GRE Composite Pipes}

After the boundary conditions, pressure and force were applied on the GRE pipe model, the next step was to perform the structural analysis. Figure 4 shows stress analysis of structure in terms of axial and hoop stress.

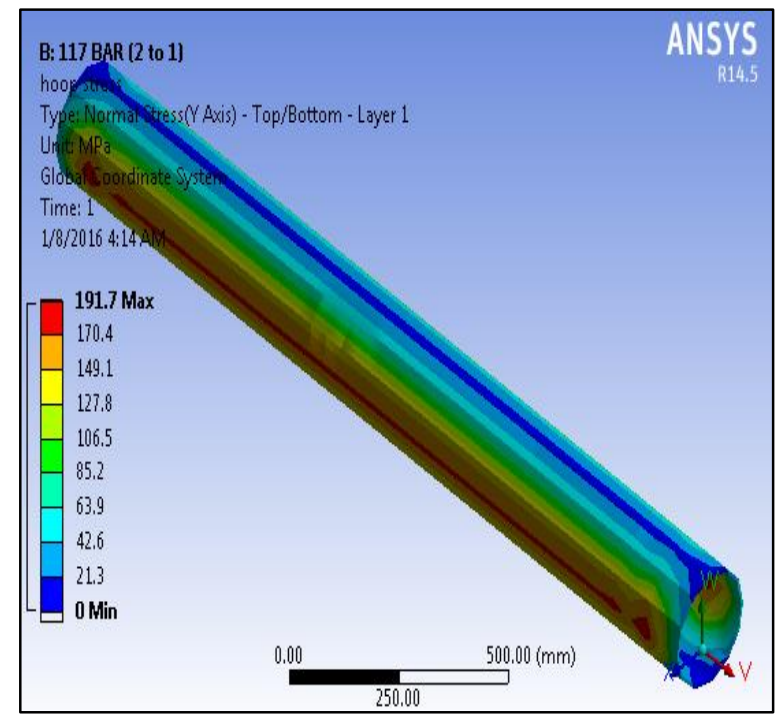

(a)

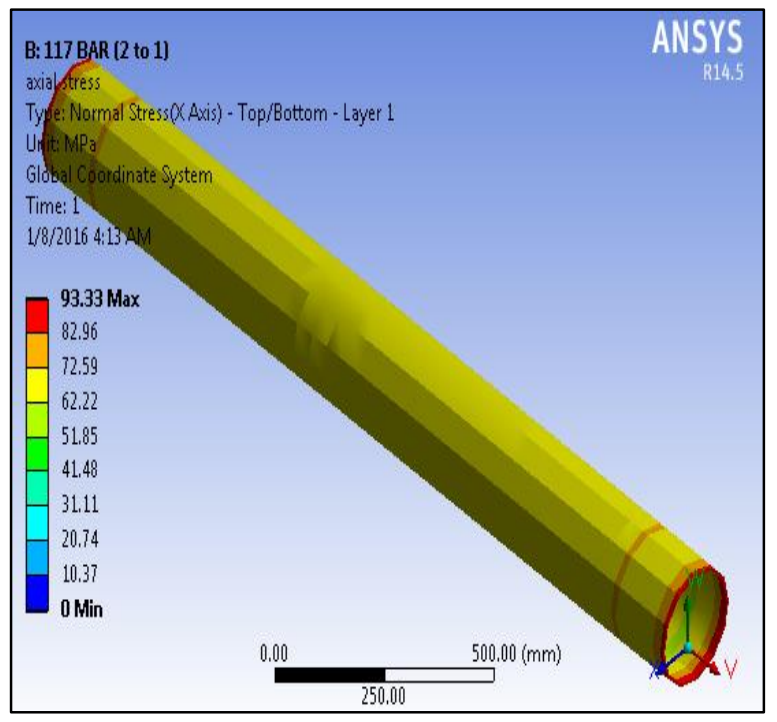

(b)

Figure 4. Structural analysis: (a) axial stress; (b) hoop stress.

Figure 5 shows the distributions of the maximum stress components for the pipe with the $\left[\mathrm{RT} / \pm 55^{\circ}{ }_{10}\right]$ lay-up configuration and Tsai-Wu failure criteria value at first ply failure (FPF) for a 2:1 stress ratio when the pipe is subjected to $11.7 \mathrm{MPa}$ internal pressure. The stress results can be plotted for the following stress component directions. Linear static analysis was performed to obtain the stress distribution in each ply, comprising of the principal stress in directions 1 and 2, and shear stress/strain components. Due to the pipe analysis obtaining a large deformation, with the deflection being negligible in comparison with the general dimensions of the pipe, the linear static analysis is acceptable [15].

\section{MATHEMATICAL MODELLING}

\section{Failure Criterion}

Many criteria can be used to predict the failure of composite materials. The accuracy of the prediction of failure depends strongly on the criteria applied [17]. There are a large number of criteria for the prediction of failure of composite materials [18], ranging from the simplest non-interactive ones, such as Tsai-Wu and Tsai-Hill. Tsai's criterion is an empirical quadratic criterion, one of the most popular failure criteria used to predict the failure of composite materials, also implemented in a few commercial finite element programs. The Tsai-Wu criterion was studied to complete the objectives in this research. This criterion provides the capability for interaction between direct and shear stresses and accounts for differences between tensile and compressive strength. 


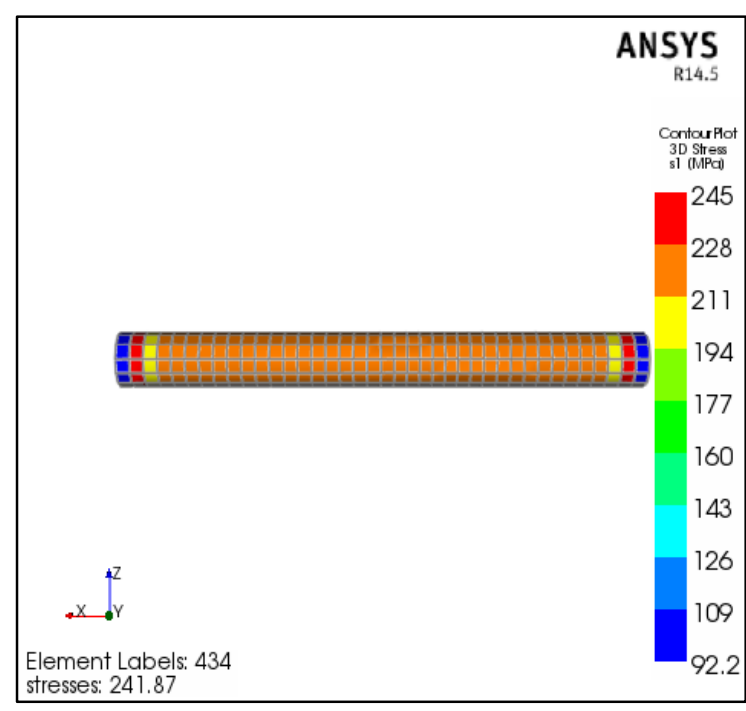

(a)

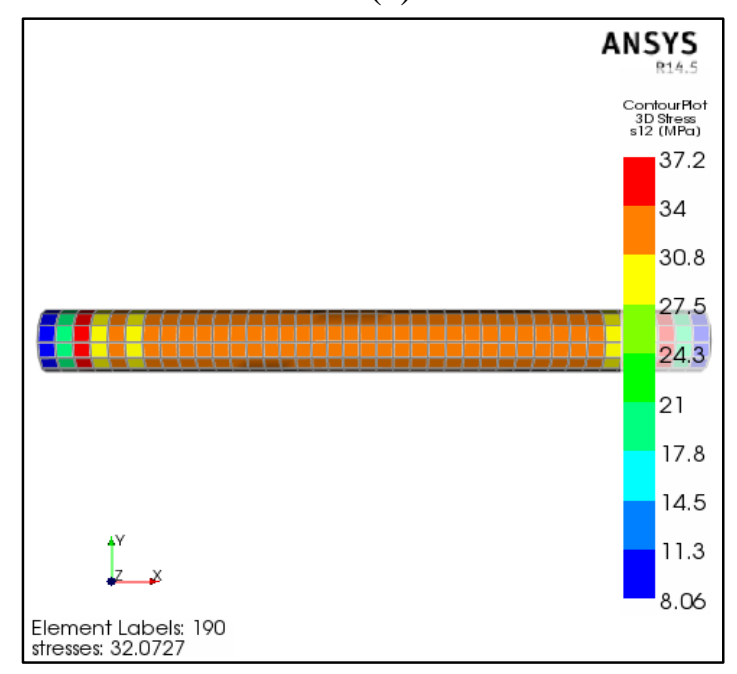

(c)

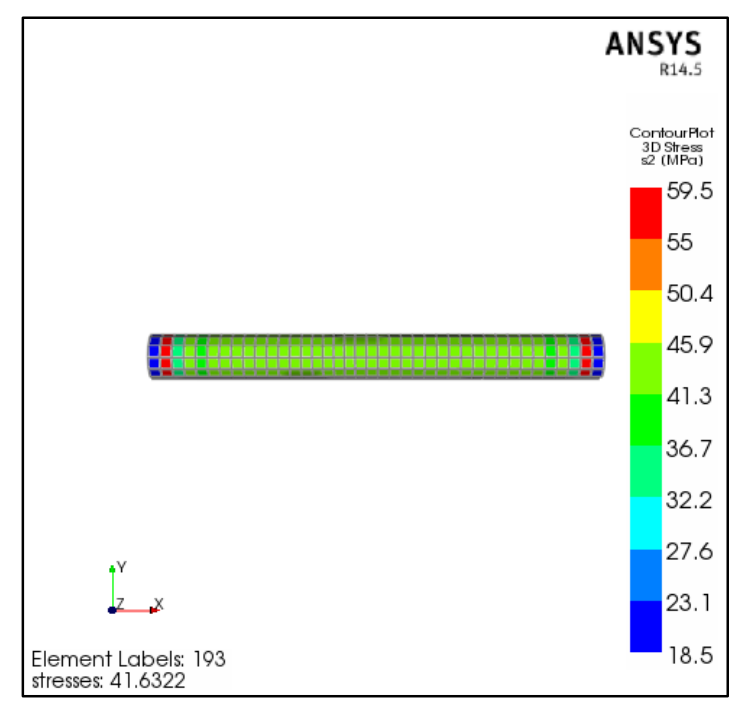

(b)

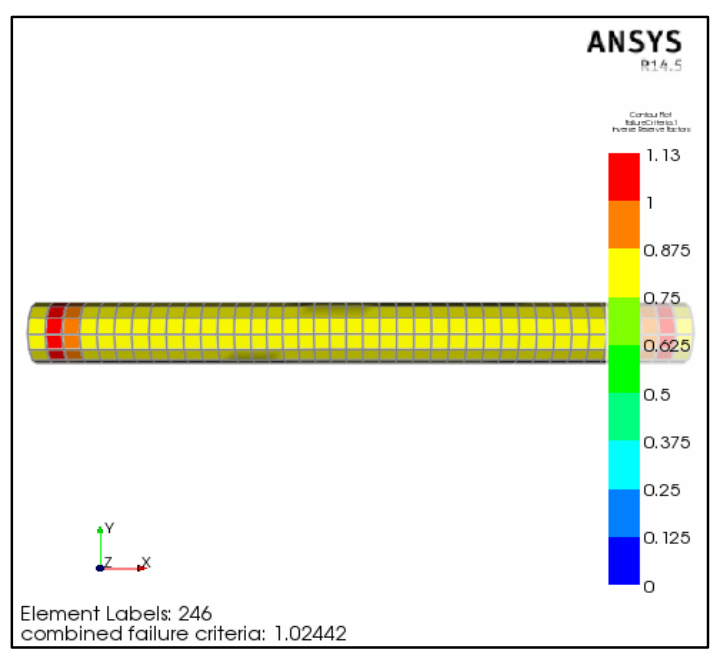

(d)

Figure 5. Stress deformation and failures: (a) Principal stress in direction 1 (s1); (b) principal stress in direction 2 (s2); (c) in-plane shear stress (s12) and (d) Tsai-Wu criterion for first ply failure.

\section{RESULTS AND DISCUSSION}

Figure 6 explains the stress-strain curve at a (2:1) stress ratio at room temperature. Roughly, the FEM has the highest hoop stress compared to the experimental and modelling (analytical) results, causing it to deviate from the straight line as shown below. The biaxial strength of GRE composite pipes is illustrated in the failure envelope of axial stress against hoop stress, as shown in Figure 7(a)-(c). These figures show the FEM and experimental result based failure envelope for the GRE pipes tested at room temperature (RT), $65^{\circ} \mathrm{C}$ and $95^{\circ} \mathrm{C}$ respectively, while the combinations of the failure envelope for RT and elevated temperatures are described in Figure 8. All the experimental data were obtained from a previous researcher. It can be seen that each of the five points of the stress ratio in the failure envelope graph has a different value of hoop and axial stress, where 
the lines indicate the stress ratios at which the tests were conducted. Overall, the failure envelopes generated from the FEM analysis and experiment showed a strong dependence on the stress ratio and tests temperature. At room temperature, the hoop stress ( $338 \mathrm{MPa})$ is over four times greater than that of the pure axial stress ( 90 MPa). This is mainly because in pure axial loading the load is strongly matrix-dominated [19]. As the stress ratio increases, the axial and hoop failure strengths also increase due to the greater loads now being taken up by the stronger fibre [20]. It is shown that under what is regarded as the optimal pipe in design loading conditions for $\pm 55^{\circ}$ wound GRE pipe, which is at 2:1 hoop to axial stress, the hoop stress is at $\sim 194 \mathrm{MPa}$. However, the highest hoop stress was recorded at 4:1 hoop to axial loading at $\sim 339 \mathrm{MPa}$, although the failure axial strength is slightly lower than that of the 2:1 loading.

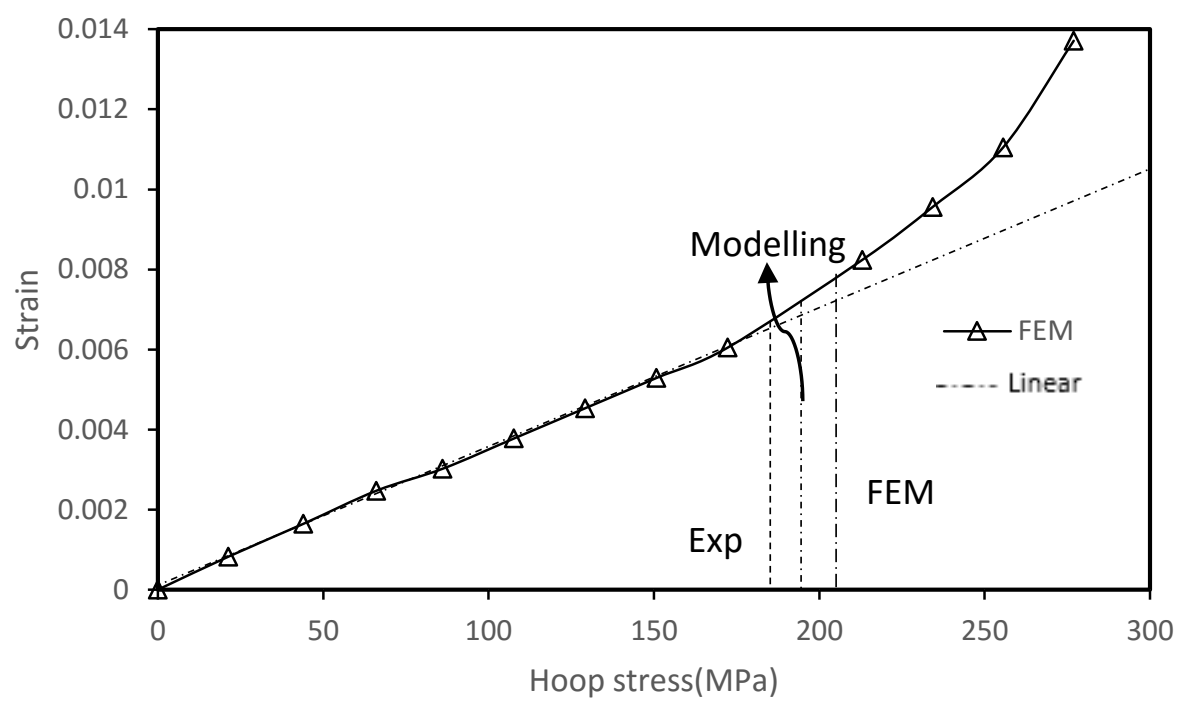

Figure 6. Stress-strain curve at (2:1) stress ratio at room temperature.

The FEM analysis at RT also registered almost constant axial failure stresses from pure axial to pure hoop loadings. This range is thought to correspond to the change in failure mechanisms from the transverse matrix at the pure hoop loading condition. Pipe failure was observed during this range of multi-axial loadings. At high axial-dominated loadings of 0:1, the FEM and experimental failure strengths are very close. This suggests that at these loading ratios, after the point at which damage commenced, the functional failure occurred very quickly, indicating rapid damage progression. In the hoopdominated loading region from the 4:1 stress ratio, the axial strength began to decrease until the pure hoop loading was reached. Both the FEM and experimental hoop strength decreased, from $339 \mathrm{MPa}$ to $297 \mathrm{MPa}$ and from $340 \mathrm{MPa}$ to $270 \mathrm{MPa}$ respectively from $4: 1$ to pure hoop loading, registering nearly $12.4 \%$ and $21 \%$ reductions. This is due to the bending of the pipe observed in this loading condition, inducing relatively high shear stresses especially near the end fittings of the pipe's compressive side [21]. Results at higher temperatures reveal that the pipe strength is generally reduced, except for the 2:1 condition. Very noticeable reductions were observed at the pure axial and pure hoop loading conditions, where the failure mode is matrix-dominated. 


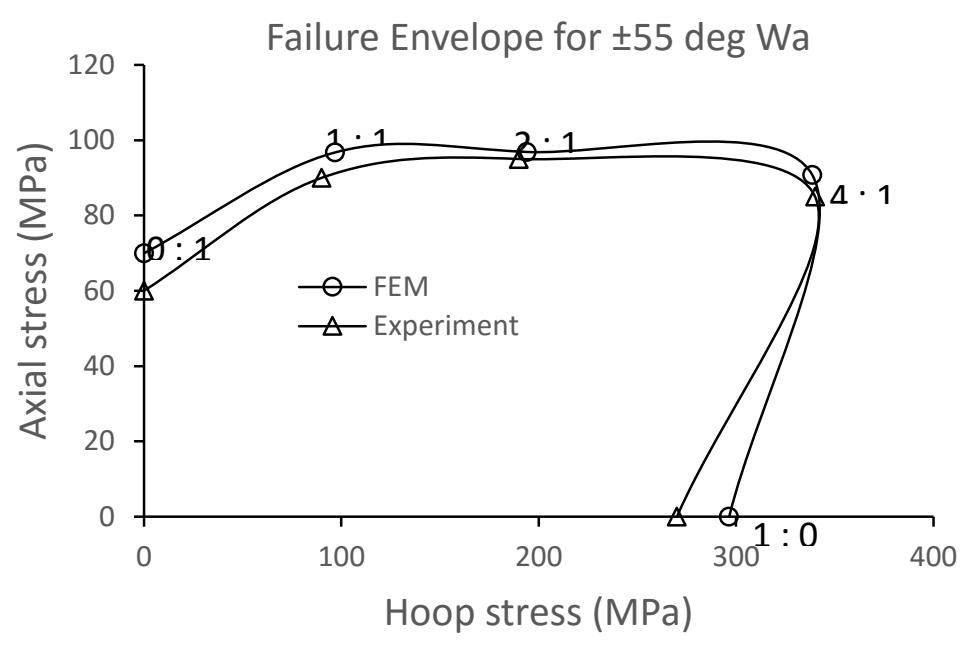

(a)

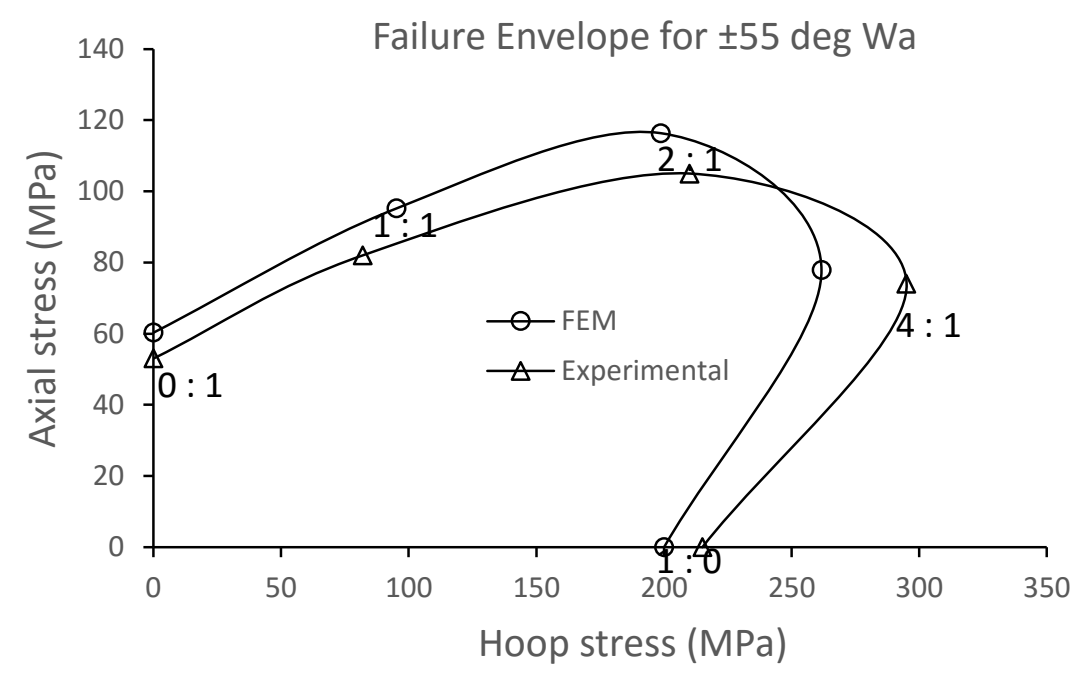

(b)

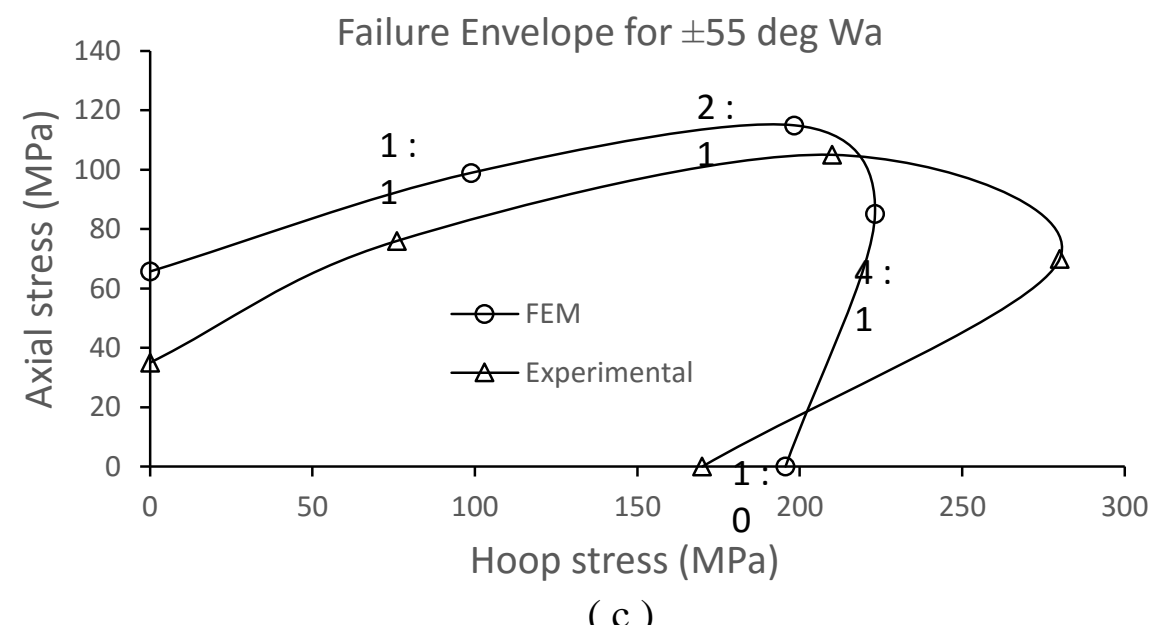

(c)

Figure 7. Failure envelope of stress distribution for GRE composite pipes at (a) RT, (b) $65^{\circ} \mathrm{C}$ and $(\mathrm{c}) 95^{\circ} \mathrm{C}$. 
The FEM analysis of the pipe for pure axial loading at room temperature decreased from $70 \mathrm{MPa}$ at $\mathrm{RT}$ to $60.3 \mathrm{MPa}$ at $65^{\circ} \mathrm{C}$ and only $40 \mathrm{MPa}$ at $95^{\circ} \mathrm{C}$, which represents an almost one-third reduction in axial strength. The hoop strength also registered a substantial decline of nearly $34 \%$, with a reduction from $296.5 \mathrm{MPa}$ at RT to a low $195.6 \mathrm{MPa}$ at $95^{\circ} \mathrm{C}$. This finding is in good agreement with work by Hale [22], who suggested that the resin matrix becomes softened at high temperatures, which significantly reduces its strength. Since the failures at stress conditions other than 2:1 are matrix-dominated $[23,24]$, this resulted in the greatly reduced pipe strength, especially under pure hoop loading and pure axial loading. In only one condition, at 2:1 hoop to axial loading, did FEM analysis points show an increase in the strength from RT at 194 $\mathrm{MPa}$ to $200 \mathrm{MPa}$ for both the $65^{\circ} \mathrm{C}$ and $95^{\circ} \mathrm{C}$ tests. Similarly, the experimental results of the pipe hoop strength also increased from $190 \mathrm{MPa}$ at RT to $210 \mathrm{MPa}$ at elevated temperatures. This is because the 2:1 loading is considered as the optimum loading condition for $\pm 55^{\circ}$ wound pipe, where most of the load is carried by the glass fibres and little by the resin matrix. It is believed that at higher temperatures the glass fibres become more ductile. This characteristic of temperature dependence causes the failure envelopes to shrink towards the origin and to become slightly narrower to accommodate the increase in strength for the 2:1 loading condition. Matrix cracking within composite laminates has been recognized as the major factor causing the reduction in stiffness of laminates.

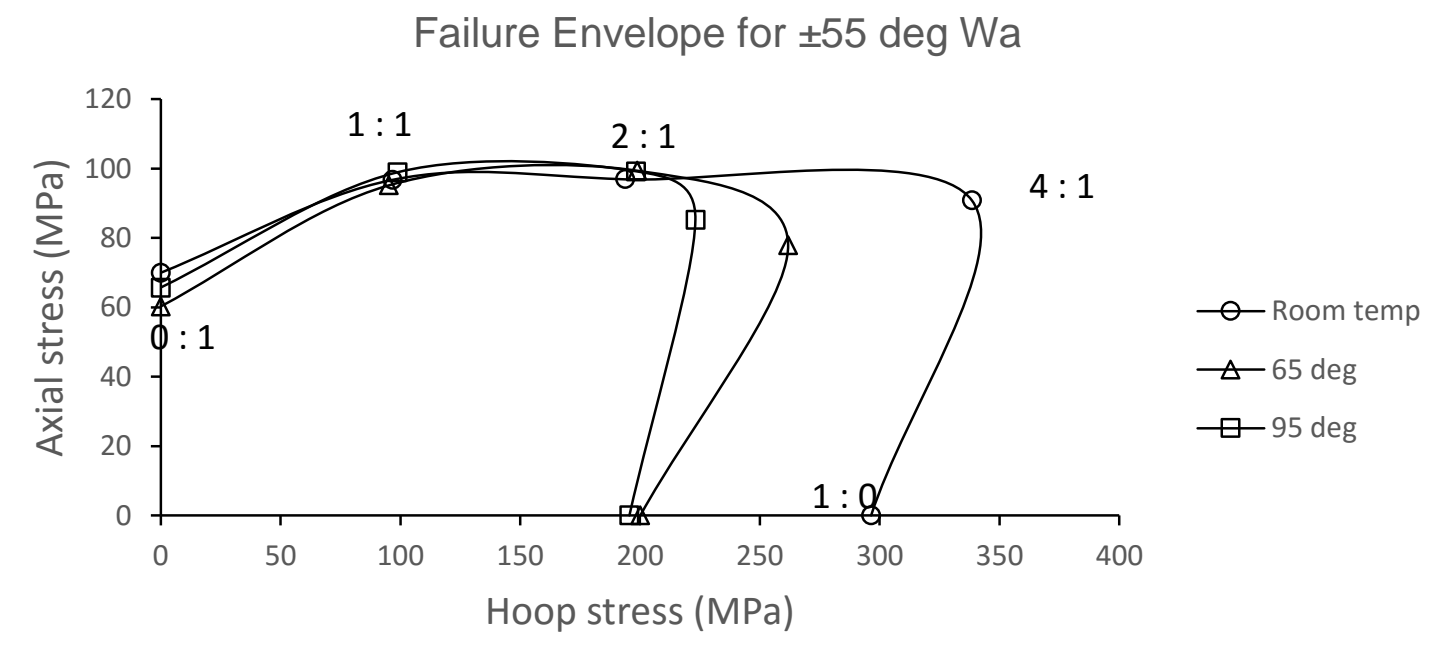

Figure 8. Combinations of failure envelope for stress distribution for GRE pipes from FEM analysis results at $\mathrm{RT}, 65^{\circ} \mathrm{C}$ and $95^{\circ} \mathrm{C}$.

\section{CONCLUSIONS}

The finite element numerical analysis allows investigation of the effects of temperature on GRE composite pipes under multi-axial loadings. After validating the developed modelling procedure, a parametric study is conducted to investigate the effects of temperature on GRE pipes under multi-axial loadings. Based on the failure envelope obtained, it was observed that the temperatures affect the strength of GRE pipes, with a lower value of hoop stress and axial stress at each temperature. Moreover, the mechanical behaviour of the GRE composite pipe changed as the temperature changed. This is because the GRE pipes become more ductile at higher temperatures and resulted in the drop in strength of the GRE pipes. In future research, other new methods should be 
studied in order to improve the strength of composite pipe even when it is situated at higher temperatures, so that temperature need no longer be a factor. In addition, we would like to improve the simulation accuracy, and we plan to achieve a nonlinear finite element analysis for the GRE composite pipe.

\section{ACKNOWLEDGEMENTS}

The authors would like to thank the School of Mechatronics Engineering, Universiti Malaysia Perlis for providing and giving a space, lab facilities and financial assistance throughout the investigation.

\section{REFERENCES}

[1] Deshmukh B, Jaju S. Design and analysis of glass fiber reinforced polymer (GFRP) leaf spring. 2011 Fourth International Conference on Emerging Trends in Engineering \& Technology: IEEE; 2011. p. 82-7.

[2] Srivastava A, Choudhary S. Design and structural analysis of Jute/E-glass woven fiber reinforced epoxy based hybrid composite leaf spring under static loading. International Journal of Mechanical Engineering and Research. 2013;3:573-82.

[3] Ramnath BV, Kokan SJ, Raja RN, Sathyanarayanan R, Elanchezhian C, Prasad $\mathrm{AR}$, et al. Evaluation of mechanical properties of abaca-jute-glass fibre reinforced epoxy composite. Materials \& Design. 2013;51:357-66.

[4] Abdul Majid MS, Daud R, Afendi M, Amin NAM, Cheng EM, Gibson AG, et al. Stress-strain response modelling of glass fibre reinforced epoxy composite pipes under multiaxial loadings. Journal of Mechanical Engineering and Sciences. 2014;6:916-28.

[5] Roslan SAH, Hassan MZ, Rasid ZA, Zaki SA, Daud Y, Aziz S, et al. Mechanical properties of bamboo reinforced epoxy sandwich structure composites. International Journal of Automotive and Mechanical Engineering. 2015;12:288292.

[6] Abdul Majid MS, Assaleh TA, Gibson AG, Hale JM, Fahrer A, Rookus CAP, et al. Ultimate elastic wall stress (UEWS) test of glass fibre reinforced epoxy (GRE) pipe. Composites Part A: Applied Science and Manufacturing. 2011;42:1500-8.

[7] Aeyzarq Muhammad Hadzreel MR, Siti Rabiatull Aisha I. Effect of reinforcement alignment on the properties of polymer matrix composite. Journal of Mechanical Engineering and Sciences. 2013;4:548-54.

[8] Wan Dalina WAD, Mariatti M, Mohd Ishak ZA, Mohamed AR. Comparison of properties of mwcnt/carbon fibre/ epoxy laminated composites prepared by solvent spraying method. International Journal of Automotive and Mechanical Engineering. 2014;10:1901-9.

[9] Basaruddin K. Uniaxial Ratcheting of Fiber Glass Reinforced Epoxy: The effect of the fiber orientation. International Conference on Applications and Design in Mechanical Engineering (ICADME) 2009. Penang, Malaysia2009.

[10] Othman RN, Wilkinson AN. The impedance characterization of hybrid cnt-silica epoxy nanocomposites. International Journal of Automotive and Mechanical Engineering. 2014;10:1832-40.

[11] Ravi Sankar H, Srikant RR, Vamsi Krishna P, Bhujanga Rao V, Bangaru Babu P. Estimation of the dynamic properties of epoxy glass fabric composites with 
natural rubber particle inclusions. International Journal of Automotive and Mechanical Engineering. 2013;7:968-80.

[12] Jeffrey KJT, Tarlochan F, Rahman MM. Residual strength of chop strand mats glass fiber/epoxy composite structures: effect of temperature and water absorption. International Journal of Automotive and Mechanical Engineering. 2011;4:504-19.

[13] Krishnan P, Abdul Majid MS, Afendi M, Gibson AG, Marzuki HFA. Effects of winding angle on the behaviour of glass/epoxy pipes under multiaxial cyclic loading. Materials \& Design. 2015;88:196-206.

[14] Wang ZD, Yao K, Deng B, Ding KQ. Theoretical studies of metal magnetic memory technique on magnetic flux leakage signals. NDT \& E International. 2010;43:354-9.

[15] Rafiee R, Amini A. Modeling and experimental evaluation of functional failure pressures in glass fiber reinforced polyester pipes. Computational Materials Science. 2015;96:579-88.

[16] GWE. Glass-Fiber Reinforced Epoxy Pipes The piping system of the future. In: GmbH Gp, editor. Moorbeerenweg, Germany: GWE pumpenboese GmbH.

[17] Zu L. Design and optimization of filament wound composite pressure vessels: TU Delft, Delft University of Technology; 2012.

[18] Laš V, Zemcik R, Kroupa T, Kottner R. Failure prediction of composite materials. Bulletin of Applied Mechanics. 2008;4:81-7.

[19] Guedes RM. An energy criterion to predict delayed failure of multi-directional polymer matrix composites based on a non-linear viscoelastic model. Composites Part A: Applied Science and Manufacturing. 2004;35:559-71.

[20] Abdul Majid M, Daud R, Afendi M, Amin N, Cheng E, Gibson A. Stress-strain response modelling of glass fibre reinforced epoxy composite pipes under multiaxial loadings. Journal of Mechanical Engineering and Sciences. 2014;6:916-28.

[21] Majid MSA, Afendi M, Daud R, Amin N, Mohamad A, Cheng E, et al. General lifetime damage model for glass fibre reinforced epoxy (GRE) composite pipes under multiaxial loading. Key Engineering Materials: Trans Tech Publ; 2014. p. 624-8.

[22] Hale JM, Shaw BA, Speake SD, Gibson AG. High temperature failure envelopes for thermosetting composite pipes in water. Plastics, Rubber and Composites. 2000;29:539-48.

[23] Majid M, Afendi M, Daud R, Gibson A, Hekman M. Effects of winding angles in biaxial ultimate elastic wall stress (UEWS) tests of glass gibre reinforced epoxy (GRE) composite pipes. Advanced Materials Research: Trans Tech Publ; 2013. p. 424-8.

[24] Abdul Majid M, Gibson A, Hekman M, Afendi M, Amin N. Strain response and damage modelling of glass/epoxy pipes under various stress ratios. Plastics, Rubber and Composites. 2014;43:290-9. 